\title{
Nothochrysinae (Neuroptera: Chrysopidae): New Larval Description and Generic Synonymy, with a Consideration of Generic Relationships
}

\author{
Catherine A. Tauber ${ }^{1,2}$ \\ ${ }^{1}$ Department of Entomology, Comstock Hall, Cornell University, Ithaca, NY 14853-2601, USA \\ ${ }^{2}$ Department of Entomology and Nematology, University of California, Davis, CA 95616, USA
}

Correspondence should be addressed to Catherine A. Tauber; cat6@cornell.edu

Received 13 February 2014; Revised 5 April 2014; Accepted 6 April 2014; Published 11 June 2014

Academic Editor: Jacques Hubert Charles Delabie

Copyright (C) 2014 Catherine A. Tauber. This is an open access article distributed under the Creative Commons Attribution License, which permits unrestricted use, distribution, and reproduction in any medium, provided the original work is properly cited.

\begin{abstract}
Semaphorant B of Kimochrysa africana (Kimmins) expresses all of the larval synapomorphies that characterize the subfamily Nothochrysinae. Except for its head markings, the larva appears identical to that of Hypochrysa elegans (Burmeister). Based on consideration of both larval and adult similarities, Kimochrysa (Tjeder) is designated to be a subjective synonym of Hypochrysa Hagen (New Synonymy). The morphological basis for a previously proposed generic subdivision of Nothochrysinae is evaluated; the results indicate that the subfamily can be organized into two generic groupings each with distinct suites of shared adult characters. As yet, apomorphic support is not forthcoming from adult characters, and, unfortunately, larvae are known from only a few genera in the subfamily.
\end{abstract}

\section{Introduction}

Chrysopid taxonomists generally agree that the subfamily Nothochrysinae is an archaic, probably monophyletic grouping [1-7]. Nevertheless, synapomorphic adult features for the subfamily have been elusive, and proposals regarding the monophyly of the subfamily largely rested on the retention of presumed plesiomorphic character states, mostly in wing venation.

In contrast, recent investigations have identified several larval features (listed in a later section) that may lend apomorphic support for the monophyly of Nothochrysinae [7-10]. These studies also indicate that larvae within the subfamily express a range of variation in their overall body form-from naked to light debris carrying.

To date, larvae are described for only three of the nine genera of Nothochrysinae; thus, the taxonomic breadth of the recently recognized morphological support for the subfamily is limited, and the range and the phylogenetic value of larval variation among genera remain unknown. In the mid 1800s,
Brauer [11] provided the first description of a larva from the Nothochrysinae; his article illustrated and described the monotypic European Hypochrysa Hagen (Semaphorant Bsecond or third instar, as Hypochrysa nobilis Heyd.). More recently, modern descriptions of the first and third instars of this species appeared [8, as Hypochrysa elegans EsbenPetersen]. All instars of the lone North American and the two European species of Nothochrysa McLachlan are described (see $[7,8,12]$ ). Finally, the first instars of Dictyochrysa fulva Esben-Petersen were described and compared with those of Nothochrysa [13].

In 2010, Duelli et al. [14] published images and biological notes on the larvae of Kimochrysa africana (Kimmins). These authors made the specimens available for morphological study and description. Here, I describe and compare the $K$. africana larvae with those known from other Nothochrysinae. As a result of the comparison, the genus Kimochrysa Tjeder is shown to be synonymous with Hypochrysa and questions arise concerning the currently held generic groupings of Nothochrysinae. These questions are addressed. 


\section{Materials and Methods}

The specimens were collected in the Republic of South Africa, Hoek-se-Berg Pass nr. Bushmans Kloof, $32^{\circ} 07^{\prime} 04.9^{\prime \prime} \mathrm{S}$, $19^{\circ} 10^{\prime} 29.7^{\prime \prime}$ E, $650 \mathrm{~m}, 2-\mathrm{X}-2004$ (see [14]). Unfortunately an early shipment of larvae was lost in the mail; the second shipment contained second instars $(n=3)$ preserved in alcohol. Upon arrival, the specimens were photographed and the external gross features were described. One of the specimens was cleared in $\mathrm{KOH}$ and transferred to glycerine for examination of fine structures and setation. Two specimens are now returned to P. Duelli, Swiss Federal Research Institute WSL, Birmensdorf/Zurich, Switzerland; the cleared specimen is in the Tauber Research Collection.

Morphological terminology and chaetotaxy followed the usage of Rousset [15], Tsukaguchi [16], Tauber et al. [17], and Monserrat and Díaz-Aranda [8]. The larval stage of the Chrysopidae typically includes three instars, the first of which (Semaphorant A) is markedly different from the latter two (Semaphorant B), which resemble each other very closely except for size and small differences in chaetotaxy. Thus, it is appropriate to compare the second instars described here with third instars of other species.

\section{Second Instar Kimochrysa africana}

3.1. Diagnosis. The K. africana larvae express the three features previously identified as potential synapomorphies for Nothochrysinae [7], including (i) antenna: terminal segment is short ( ten times shorter than remainder of antenna), (ii) antenna: terminus has a group of small apical setae, not an elongate seta, (iii) labial palpus: terminal segment has more than three lateral sensilla.

As Duelli et al. [14] noted, the K. africana larvae closely resemble those of the nothochrysine $H$. elegans in their elongated, naked bodies and their bright green coloration. They also share the following morphological features: (i) head: primary setae are blunt, (ii) thorax: lateral tubercles (LTs) are absent, (iii) abdomen: LTs are absent, (iv) abdomen: laterodorsal tubercles are absent or very small and with only one seta, and (v) types of setae: thoracic notal setae are short, blunt to slightly clavate, and abdominal (A1-A6) submedian setae are short, blunt to clavate, without hooks.

The most notable difference between the larvae of the two species is that $K$. africana lacks the dark, elongated median head marking of $H$. elegans.

\subsection{Description}

3.2.1. Body (Figures 1(a) and 1(b)). Length $\sim 5.9-6.9 \mathrm{~mm}$ (measured in lateral view through spiracles), depth $\sim 0.85-$ $1.1 \mathrm{~mm}$ (thickest section of abdomen). Bright green coloration of living specimens [14] faded in preserved specimens; dorsal surface largely cream-colored to tan, with pronotal sclerites brown, with pair of broad, reddish brown, vertical bands along lateral margins, extending from cervix to tip of A9. All setae short, smooth, pale, and of two types: "blunt/clavate" with blunt or slightly enlarged tip, usually erect and straight (primary cranial setae, dorsal thoracic, and abdominal setae (submedian setae, SMS)); "simple" with acute tip, usually erect and slightly curved (setae on cephalic appendages, some small, usually secondary, cranial setae, some very small setae on thoracic notum, setae on legs, posterior part of A9, A10, and ventral setae).

3.2.2. Head (Figures $1(d)-1(f), 2(a)$ and 2(b)). Dorsum creamcolored, with light brown to brown markings as in Figures 1(d) (dorsal), 1(e) (ventral), and 1(f) (lateral); eyes with stemmata clear, surrounding integument dark brown; cranium tapered posteriorly and roughly triangular, with rounded posterior (dorsal view); width (across eyes) $\sim 0.60-0.64 \mathrm{~mm}$, length (dorsum) $\sim 0.52-0.54 \mathrm{~mm}$, and depth (midregion to top of eye) $\sim 0.13 \mathrm{~mm}$; base fully exposed. Anterior margin of labrum protruding slightly, straight anteriorly, and rounded laterally. All dorsal primary cephalic setae present (Figures 2(a) and 2(b)), blunt to slightly knobbed apically; two Vx setae present; labrum with two or three pairs of setae (one mesally and two laterally); dorsum with several secondary setae: one long, indistinguishable from posterior primary setae, others very short, mesal to S6. Ventral primary setae (S9, S10) present; S8 absent.

3.2.3. Cephalic Appendages (Figures 1(d)-1(f), 2(a) and 2(b)). Mandible long, thin, with length $\sim 1.0-1.1 \mathrm{~mm}$, width $0.10 \mathrm{~mm}$; ratio of mandible length to head width $1.54-1.63$; ratio of mandible length to head length (dorsal) 1.90-1.00. Mandible slightly upturned distally, with single acute basolateral seta; terminus sharp, with six teeth. Antennal length $0.90-0.97 \mathrm{~mm}, \sim 1.7-1.8 \mathrm{x}$ length of cranium; width $\sim 0.03-$ $0.04 \mathrm{~mm}$ (at widest part of pedicel); scape with straight sides, two pairs of distal setae (one lateral, other mesal); pedicel long, about 17-19x length of flagellum, slightly broader than the base of flagellum; flagellum short, stubby, basal flagellomere with or without mesal seta, terminus with short basolateral seta, several very short setae. Labial palp long, slender, $\sim 0.75 \mathrm{x}$ length of mandible; basal segment with one short, dorsal seta basally, three setae distally (two mesal, one lateral); middle segment long, with long, undivided basal subsegment bearing five setae, five shorter mesal subsegments, with one seta mesally, elongated terminal subsegment, with two long setae distally; terminal segment one-third length of middle segment, slightly tapered distally, terminus with several very small setae; palpiger erect, with relatively straight sides, with one mesal seta, one lateral seta; mentum with smooth plate mesal to stipes, lateral to palpiger, with three pairs of long setae; cardo and stipes elongate, narrow, longitudinally arranged; cardo behind stipes. Cervix expanded laterally, ventrally, withdrawn from cranium dorsally; with pair of setae dorsolaterally, two pairs laterally, two pairs ventrally.

3.2.4. Thorax (Figures 1(c) and 3(a)). Lateral tubercles absent; dorsum with scattered, short, blunt to slightly clavate setae; primary setae unidentified (except as noted below). Legs (Figure 1(g)) cream-colored; coxae with diffuse, light brown marks anterolaterally; trochanter, femur with dark brown, longitudinal stripes anterodorsally, posterodorsally, with dark vertical stripe at tip of segment; tibia with dark brown vertical 


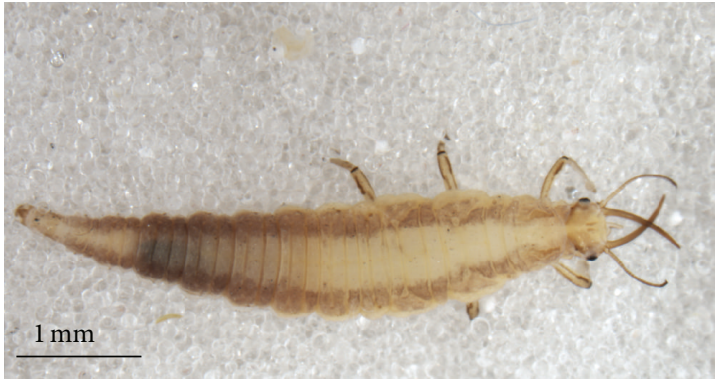

(a)

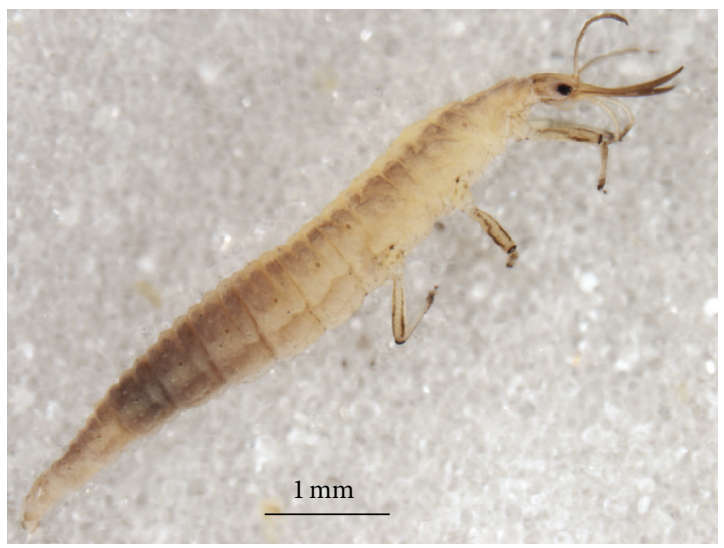

(b)

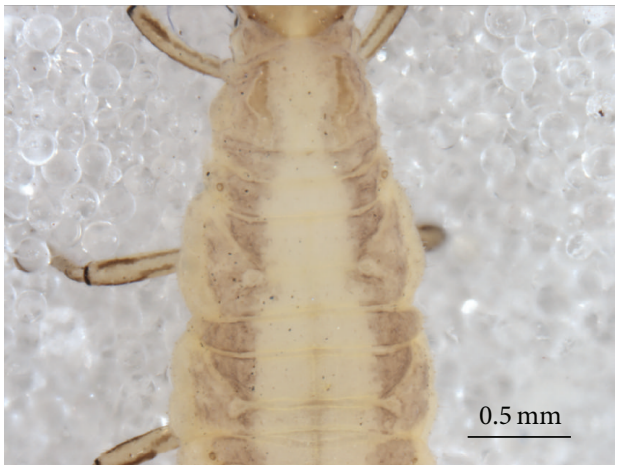

(c)

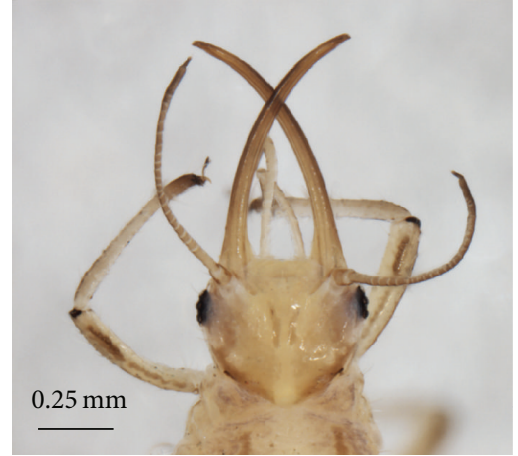

(d)

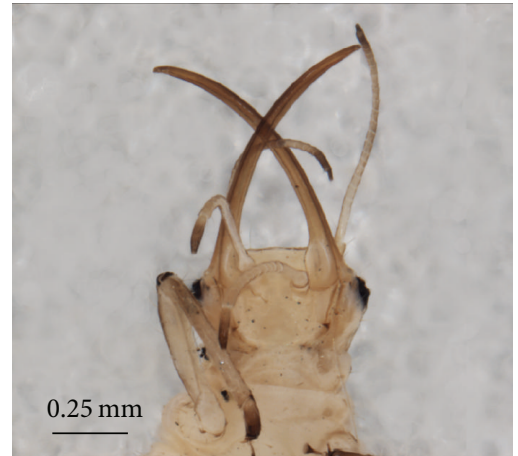

(e)

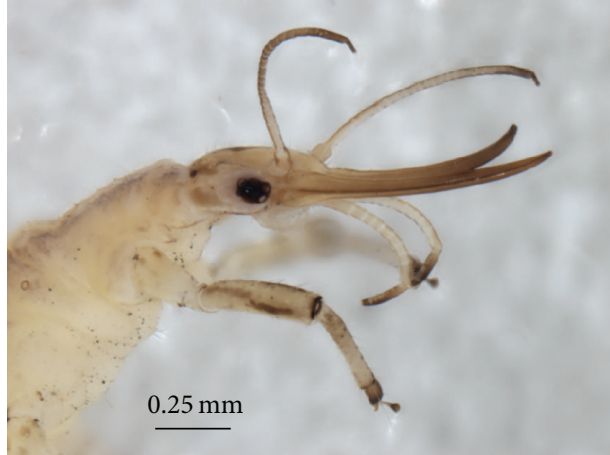

(f)

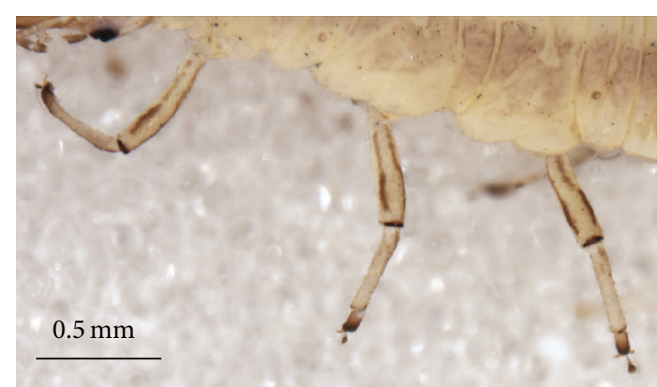

(g)

Figure 1: Hypochrysa africana Kimmins, second instar (Hoek-se-Berg Pass, South Africa). (a) Body, dorsal. (b) Body, lateral. (c) Thorax, dorsal. (d) Head, dorsal. (e) Head, ventral. (f) Head, lateral. (g) Legs, dorsal. 


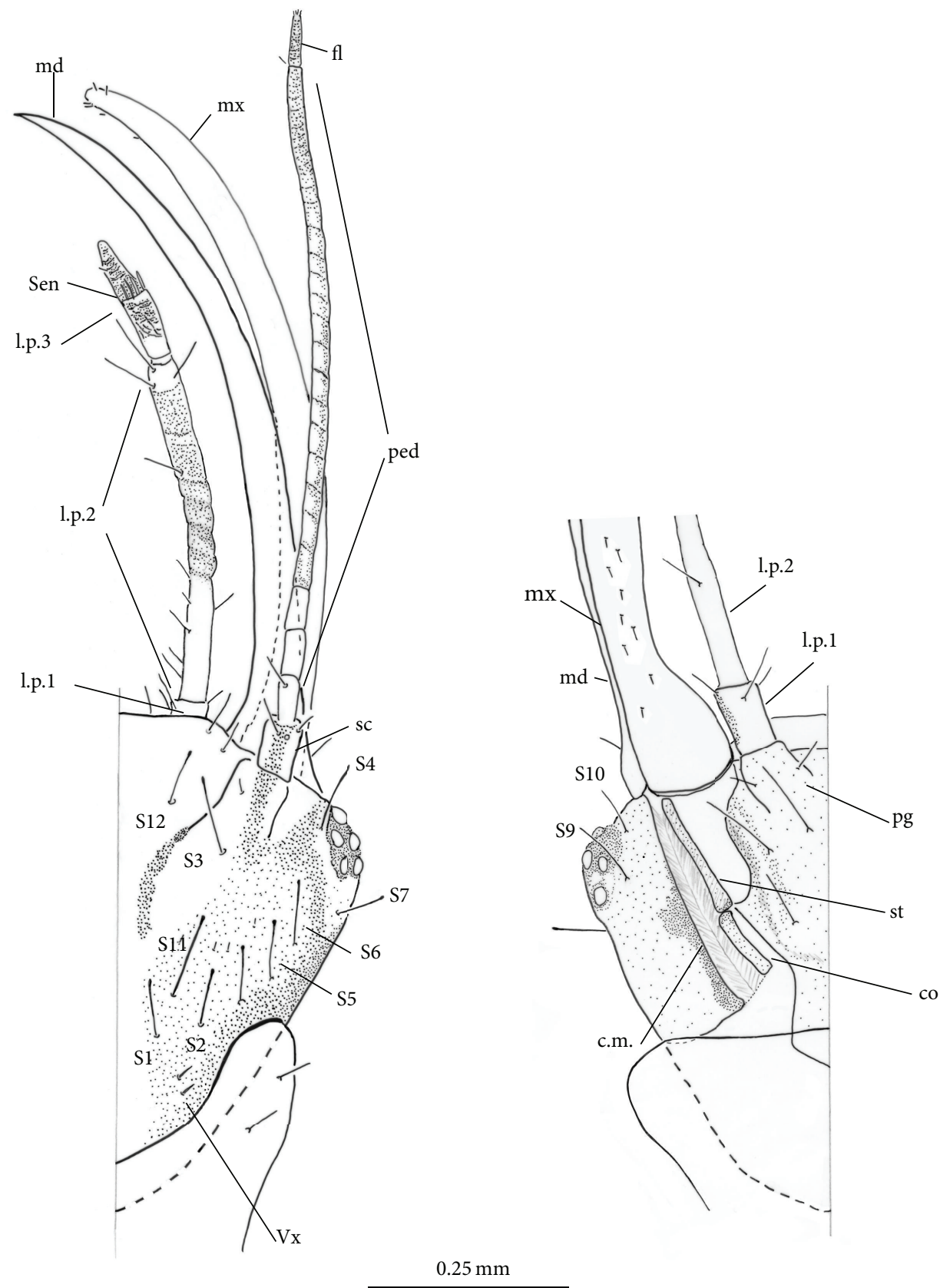

(a)

(b)

Figure 2: Head of Hypochrysa africana Kimmins, second instar. (a) Dorsal. (b) Ventral. Scale applies to both (a) and (b). Abbreviations: co, cardo; c.m., cranial margin; fl, flagellum; l.p.x, labial palpus, number of segment; md, mandible; mx, maxilla; ped, pedicel; pg, palpiger; sc, scape; sen, sensilla; stp, stipes; Sx, primary seta, number; Vx, Vx setae.

stripe basally, short, diffuse, light brown, longitudinal marks anterobasally, posterobasally; tarsus, claw, empodium dark brown.

Prothorax (T1) with two well delineated subsegments separated by transverse depression. Scl brown, elongated, extending almost to the full length of anterior subsegment, narrow anteriorly, posteriorly, broad mesally, embedded within lateral stripe, delineated laterally by curved, creamcolored strip. Sc2 elongated, narrow, extending posteriorly to margin of anterior subsegment.

Mesothorax (T2) consisting of three well delineated subsegments separated by distinct depressions. Anterior 


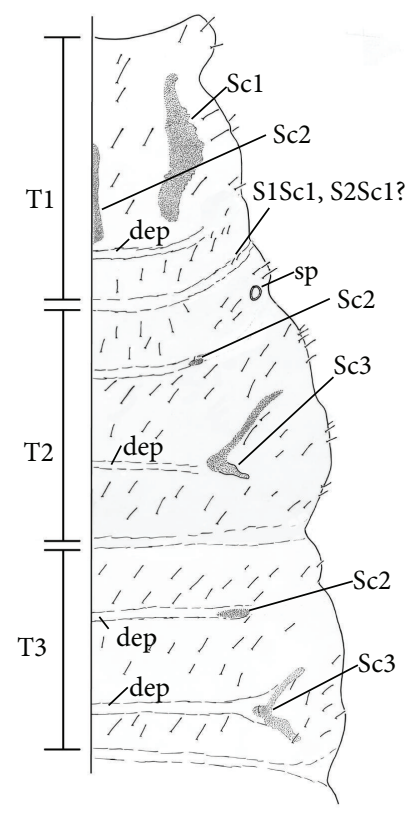

(a)

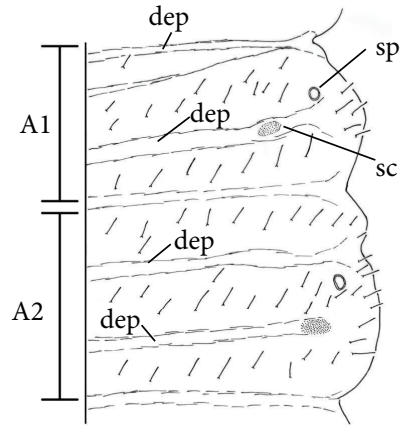

(b)

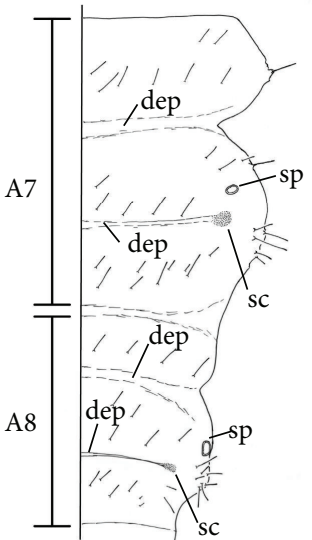

(c)

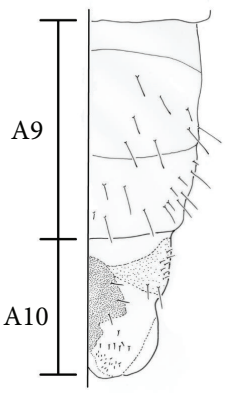

(d)

Figure 3: Thorax and abdomen (dorsal) of Hypochrysa africana Kimmins, second instar. (a) Thorax. (b) First and second abdominal segments. (c) Seventh and eighth abdominal segments. (d) Ninth and tenth abdominal segments. Abbreviations: Ax, number of abdominal segment; dep, smooth-surfaced, intrasegmental depression between subsegments; S1Sc1, S2Sc1, first and second primary setae on Sc1, Sc2, and Sc3, the first, second, and third primary sclerites of each segment; sc, abdominal sclerite; sp, spiracle; Tx, number of thoracic segment.

subsegment with pair of small setae on anterior margin (probably S1Sc1, S2Sc), but Sc1 not distinguished; spiracles simple, sessile, circular, brown, with cylindrical, tapering atrium. Second subsegment with pair of small sclerites (Sc2) on anterior margin, each with single, very small seta (S1Sc2); subsegment separated mesally from posterior subsegment by transverse depression with pair of large, bifurcating sclerites (Sc3) laterally. Sc3 with anterior arm extending anterolaterally, posterior arm extending posterolaterally, each toward edge of subsegment; center of Sc3 marked with brown, embedded in lateral stripe, entirely delineated by creamcolored area.

Metathorax (T3) consisting of three well delineated subsegments separated by transverse depressions each with pair of transversely elongated sclerites (Sc2, Sc3) laterally. Sc3 large, with bifurcating arms-anterior arm extending anterolaterally, posterior arm extending posterolaterally, each toward edge of segment; center of sclerite marked with brown, embedded in lateral stripe, entirely delineated by cream-colored area.

3.2.5. Abdomen (Figures 3(b)-3(d)). Lateral tubercles (LTs), laterodorsal tubercles (LDTs) absent; spiracles (A1-A8) circular, sessile, with simple, cylindrical, tapering atrium. Each segment (A1-A7) divided into three subsegments separated by transverse depressions; spiracle located laterally on dorsum of second subsegment; second, third subsegments separated by pronounced depression bearing pair of clear sublateral sclerites. A1: anterior subsegment small, spindle shaped, separated from second subsegment by small depression; dorsum with single pair of SMS; second, third subsegments longer, broader, similar in size and setation to those of A2, A3. A2-A8: subsegments roughly quadrangular, of similar size, extending to margin of segment, separated from adjoining subsegments by pronounced depressions; dorsum of each subsegment with five (four on anterior subsegment of A8) to 14 pairs of SMS. A4-A8: pleural region (dorsal region of second and third subsegments) with cluster of four to seven short setae. A9: cylindrical, with three subsegments (dorsal view); anterior subsegment without setae; posterior two subsegments sclerotized, with setae; mesal subsegment with $\sim$ seven pairs of dorsal setae; posterior subsegment with $\sim 12$ pairs of dorsal setae, about half of them lateral. A10: dorsum with transverse brown band, separated mesally by large arrow-shaped, darker brown mark; segment with $\sim$ five pairs of setae, numerous microsetae. All segments with few small "simple" or "denticulate" setae. Venter with subsegmentation 
lightly demarcated (A1-A4) or without demarcation (A5A9); each segment with numerous "simple" setae, usually longer than dorsal setae.

\section{Discussion}

4.1. Synonymy Based on Larval Characters. A comparison of the K. africana and $H$. elegans larvae (Semaphorant B) does not reveal any significant, generic-level differences; for comparison, see [8]. Indeed, the larvae of the two species appear to differ largely in their head markings. Because of their similarity, I consider them congeneric, and hereby, Kimochrysa Tjeder becomes a junior (subjective) synonym of Hypochrysa Hagen (New Synonymy). The type species of the genus is Chrysopa nobilis Schneider, and the species under study here reverts to its original name, Hypochrysa africana Kimmins.

Given this generic synonymy, the questions now are as follows. (i) Is this synonymy, which is based on larval characters, also supported by adult morphological characters? And, (ii) how does the synonymy affect current understandings of relationships among the genera within Nothochrysinae?

4.2. Support from Adult Morphology? Of the several adult characters purported to differentiate Kimochrysa and Hypochrysa, two tend to support the synonymy; one weakly contradicts it, and three are neutral (either variable or without sufficient comparative information) as follows:

consistent: wing venation [21]; spiracle of eighth abdominal segment (female) - opening on the eighth tergite versus on membrane (see [4]; also see Table 1).

contradictory: ninth tergite and ectoproct (male and female) - fused versus separate (see $[1,4,21]$; also see Table 1).

neutral: ectoproct (male)—with versus without a long, slender "appendage" (apodeme) [21]; subgenitale (female)-sclerotized versus unsclerotized [21]; microtholi (domelike cuticular glands) on male abdomen present versus absent (see [4], also see Table 1).

Below I discuss the perspectives of two sets of authors who provided evidence for separating the genera: (i) Tjeder [21] and (ii) Brooks and Barnard [2] and Brooks [4].

4.2.1. Tjeder's Perspective. Tjeder [21] described Kimochrysa on the basis of adult specimens of three South African species. His generic description noted similarities in the wing venation of Kimochrysa and Hypochrysa, but he felt that significant differences in their male terminalia required placing them in separate genera. Specifically, he mentioned (i) tergite 9+ectoproct-separate in Kimochrysa (as opposed to fused in Hypochrysa, both sexes), (ii) male ectoproct in Kimochrysalacking a long, slender "appendage" (probably the apodeme) that occurs in Hypochrysa, and (iii) subgenitale (female)unsclerotized in Kimochrysa (as opposed to sclerotized in Hypochrysa).

Of Tjeder's above three characters, subsequent studies have shown that the first continues to provide the strongest (albeit weak) support for the separation of Kimochrysa from Hypochrysa. In males of $H$. elegans the T9+ect is fused, and in Kimochrysa impar (Tjeder) they are separate (males are undescribed for the other two Kimochrysa species) (Table 1). In females, the structures are partially fused in $H$. elegans and separate in all three species of Kimochrysa. It should be noted that, within at least two genera of Nothochrysinae (Pimachrysa Adams (males) and Nothochrysa (females)), this character is known to express interspecific variation. Consequently, given the small number of studied species within Hypochrysa and Kimochrysa (males: $n=1$ for each genus; females: $n=4$, with one showing an intermediate condition) (Table 1), this character lends only weak support for separating the two genera.

The second character (an elongate male ectoproct) is reported from $H$. elegans $[1,23]$ but not from any other species in Nothochrysinae [2, 4]. Thus, although this character distinguishes $H$. elegans males from the single species of Kimochrysa whose males are studied, its phylogenetic value at the generic-level (versus species-level) remains open.

The third character (sclerotized subgenitale) also is of questionable value at this time. Tjeder illustrated the tips of the subgenitale of the three Kimochrysa species. However, he was not specific about what he meant by the character and he did not include equivalent drawings of the Hypochrysa subgenitale for comparison. Subsequent drawings and descriptions by other authors neither provide comparative information, nor mention any differences between the subgenitale of Hypochrysa and Kimochrysa [2, 23]. Second, the character state of the genitale has not been reported for species in other genera of Nothochrysinae for meaningful comparison. In sum, the generic-level value of the character needs further evaluation.

4.2.2. Brooks and Barnard's Perspective. In subsequent studies, Brooks and Barnard [2] and Brooks [4] retained Kimochrysa's distinction as a genus, apparently based on three characters. First, like Tjeder [21], they noted that the condition of the ninth tergite and ectoproct differentiated Hypochrysa (fused) from Kimochrysa (whose structures they considered partially fused). As stated above, this character currently has little informative value regarding the synonymy.

The second character was the presence or absence of microtholi on the male abdomen. This character differs between the single Kimochrysa species with known males (microtholi absent) and $H$. elegans (microtholi present) (Table 1). However, the condition is highly variable among the genera of Nothochrysinae both within and outside the group that contains Hypochrysa (Table 1). Thus, the character does not provide strong support either for or against the synonymy.

The third character concerns the placement of the spiracular opening on the female eighth abdominal segment-on 
TABLE 1: Summary of adult characters currently used for classifying Nothochrysinae. All known species are included.

\begin{tabular}{|c|c|c|c|c|}
\hline \multirow{3}{*}{ Species name } & \multicolumn{4}{|c|}{ Character } \\
\hline & \multicolumn{2}{|c|}{$\mathrm{T} 9+$ ect $^{*}$} & \multirow{2}{*}{ Microtholi $^{* *}$} & \multirow{2}{*}{ Spiracle ${ }^{* * *}$} \\
\hline & Male & Female & & \\
\hline \multicolumn{5}{|l|}{ Nothochrysa grouping } \\
\hline \multicolumn{5}{|l|}{ Asthenochrysa } \\
\hline viridula (Adams) & $+[3]$ & $-[3,18]$ & $-[3]$ & $-[3]$ \\
\hline \multicolumn{5}{|l|}{ Dictyochrysa } \\
\hline fulva Esben-Petersen $^{\dagger}$ & $+[2,19]$ & $+[19]$ & $?$ & $-[19]$ \\
\hline latifascia Kimmins & $+[20]$ & $?$ & $?$ & $+[19]$ \\
\hline peterseni Kimmins & $+[19]$ & $+[2]$ & $?$ & $+/-[19]$ \\
\hline \multicolumn{5}{|l|}{ Hypochrysa } \\
\hline africana Kimmins ${ }^{\dagger}$ & $?$ & $-[2,21,22]$ & $?$ & $+[2,21]$ \\
\hline elegans (Burmeister) ${ }^{\dagger}$ & $+[2,23]$ & $+/-[2,23]$ & $+[2,23]$ & $+[2,23]$ \\
\hline impar (Tjeder) & $-[2,21]$ & $-[21]$ & $-[2]$ & $+[21]$ \\
\hline raphidiodes (Tjeder) & $?$ & $-[21]$ & $?$ & $+[21]$ \\
\hline \multicolumn{5}{|l|}{ Nothochrysa } \\
\hline californica Banks ${ }^{\dagger}$ & $+[1]$ & $?[3]$ & $+[1]$ & $?$ \\
\hline capitata (Fabricius) $^{\dagger}$ & $?$ & $+[2]$ & $+[2]$ & $?$ \\
\hline fulviceps (Stephens) $^{\dagger}$ & $+[2,23]$ & $-[23]$ & $+[2,23]$ & $+[23]$ \\
\hline indigena Needham & $+[24]$ & $?$ & $?$ & $?$ \\
\hline sinica C.-k. Yang & $?$ & $-[25]$ & $?$ & $+[25]$ \\
\hline turcica Kovanci and Canbulat & $+[26]$ & $-[26]$ & $?$ & $+[26]$ \\
\hline \multicolumn{5}{|l|}{ Triplochrysa } \\
\hline pallida Kimmins & $+[2]$ & $-[19]$ & $-[2]$ & $+[2]$ \\
\hline kimminsi New & $+[19]$ & - (prob.) [19] & $?$ & $+[19]$ \\
\hline \multicolumn{5}{|l|}{ Pamochrysa grouping } \\
\hline \multicolumn{5}{|l|}{ Leptochrysa } \\
\hline prisca Adams and Penny & $?$ & $-[18]$ & $?$ & $-[3]$ \\
\hline \multicolumn{5}{|l|}{ Pamochrysa } \\
\hline stellata Tjeder & $-[21]$ & $-[2,21]$ & $-[2]$ & $-[21]$ \\
\hline \multicolumn{5}{|l|}{ Pimachrysa } \\
\hline albocostalis Adams & $-[1]$ & $?$ & $+($ prob. $)[1]$ & $?$ \\
\hline fusca Adams & $-[1,2]$ & $-[1,2]$ & $+[1,2]$ & $-[1,2]$ \\
\hline grata Adams & $?$ & $-($ prob.) $[1]$ & $?$ & $?$ \\
\hline intermedia Adams & $?$ & $-($ prob.) $[1]$ & $?$ & $?$ \\
\hline nigra Adams & $+/-[1]$ & $-($ prob.) $[1]$ & $+[1,2]$ & $?$ \\
\hline
\end{tabular}

Characters: ${ }^{*}$ tergite 9 and ectoproct: fused $(+)$, unfused $(-)$, partially fused $(+/-) ;{ }^{* *}$ microtholi on male sternites: present $(+)$, absent $(-) ;{ }^{* * *}$ location of spiracular opening on female eighth abdominal segment: on membranous pleuron below T8 (+), on T8 $(-)$, spanning both T8 and the membrane below (+/-); male or female unknown or character state not reported (?). ${ }^{\dagger}$ Species with larvae described. Numbers in square brackets: references.

the membrane versus on the tergite. For all know species of Hypochrysa and Kimochrysa, the spiracle opens on the membrane (Table 1); thus, it is consistent with the new synonymy.

4.3. Relationships among Genera of Nothochrysinae. The new synonymization of Kimochrysa with Hypochrysa led to a review and reevaluation of the current generic groupings within Nothochrysinae and the characters used to support the groupings. Previously, the subfamily was proposed to contain a derived "monophyletic" group of five genera (the "Nothochrysa group") that included Hypochrysa and that was supported by characters presumed to be apomorphic. The four remaining genera, including Kimochrysa, were considered less derived and lacked apomorphic support [4]. The present findings favor the notion that the subfamily contains two generic groupings that are similar but not identical to those listed earlier. Moreover, the strength of the "apomorphic" support for the groupings is questioned for two main reasons. First, ancestral states for the presumed apomorphies lack strong supporting evidence. Second, the characters exhibit variation within the generic groupings and sometimes even within genera.

Below is a summary of the now tentative groupings within Nothochrysinae followed by a discussion of the underlying 
support and a recommendation for fuller comparative studies.

4.3.1. Groupings of Nothochrysinae Genera. Nothochrysinae is now proposed to contain two relatively distinct groupings of genera.

(i) Nothochrysa grouping. This category contains five genera: Asthenochrysa Adams, Dictyochrysa EsbenPetersen, Hypochrysa Hagen (including Kimochrysa), Nothochrysa McLachlan, and Triplochrysa Kimmins. Larvae have been described for three of the genera [7].

(ii) Pamochrysa grouping. This category contains three genera: Leptochrysa Adams and Penny, Pamochrysa Adams, and Pimachrysa Adams. Larvae are undescribed.

4.3.2. Supporting Characters. To provide perspective and encourage stronger comparative morphological studies, the three presumed "apomorphic characters" for these groupings are discussed below.

(i) Character number 1-ninth tergite (T9) and ectoproct of both sexes fused (versus separate). The ancestral state of this character is not determined, but an unfused condition has been considered plesiomorphic for Chrysopidae [2]. Among three neuropteran families considered to be related to Chrysopidae $[5,6,27,28]$, the T9 and ectoproct are separate in Polystoechotidae and variable (fused or unfused) in Hemerobiidae and Osmylidae [27, 29-32]. The fused character state occurs in various taxa of all three chrysopid subfamilies, including the two that are considered basal (Nothochrysinae and Apochrysinae) (for phylogenetic relationships among chrysopid subfamilies, see $[5,6]$; for the distribution of morphological features, see $[2,33,34])$.

From the available literature, a fused condition occurs in males of all genera in the Nothochrysa grouping and in females of most genera. The condition is largely absent from both males and females of the Pamochrysa grouping (Table 1). The most parsimonious conclusion from the distribution of the features is that the fused T9 and ectoproct began to evolve within males of the Pamochrysa grouping, but that the presumed plesiomorphic state (separate T9 and ectoproct) was largely retained by both males and females. Apparently, full fusion appeared in males and fusion began in females during or soon after the differentiation of the Nothochrysa grouping.

The variability (especially partial fusion) in the expression of the trait may reflect differences in the degree of integumental sclerotization, rather than in the actual fusing of segments. It is well known that chrysopid adults become more sclerotized as they mature (often requiring a period of several weeks after emergence) and that their patterns of sclerotization vary considerably, individually and with age $[1$, 35-37]. Thus, caution is necessary in scoring and interpreting this character.

(ii) Character number 2-male sternites with microtholi being present (versus absent). Microtholi are not known from Neuroptera other than the Chrysopidae, and their absence is probably the basal state for the family. Within the Chrysopidae, microtholi are usually, but not always, absent in Apochrysinae males [2,34], and their occurrence is highly variable among the Chrysopinae and Nothochrysinae (see [2]; also see Table 1). It is not clear why Brooks [4] considered this feature as an apomorphy for the Nothochrysa group, when earlier Brooks and Barnard [2] reported several genera in the group as being without microtholi and it was known that the structures occur within Pimachrysa. Thus, the feature's pattern of occurrence is not consistent with its identification as an apomorphy for the subfamily Nothochrysinae or for either of its proposed generic groupings.

(iii) Character number 3-female with spiracle on eighth abdominal segment opening on membrane (versus on tergite). The spiracular opening is consistently on the eighth tergite in Osmylidae $[25,27,29,38]$ and Polystoechotidae $[30,32]$ but its placement shows significant variation within Hemerobiidae [27, 31]. Among the Chrysopidae, the opening is on the membrane throughout the Apochrysinae and in most Chrysopinae and its placement is variable within Nothochrysinae see $[4,23,35]$; also (Table 1). The presumed, but as yet unconfirmed, plesiomorphic state for the Chrysopidae is for the eighth abdominal spiracle to open on the tergite [4].

In Nothochrysinae, a spiracular opening on the eighth female tergite typifies the Pamochrysa grouping; however the numbers of exemplars/genus are very small $(n=$ 1 /genus). In the Nothochrysa grouping, a spiracular opening on the pleural membrane appears to typify three of the five genera (Hypochrysa, Nothochrysa, and Triplochrysa), but in Dictyochrysa it is variable, and it is absent from the single species of Asthenochrysa (Table 1). An interesting intermediate situation occurs in Dictyochrysa peterseni Kimmins; in this species the spiracular opening appears to span the membrane and the tergite [19, Figure 66]. Thus, although Brooks may be correct in his proposal [4] that the spiracular opening on the membrane is a "stem apomorphic character" for the "Nothochrysa group," it appears more likely that the character evolved within the Nothochrysa grouping after its differentiation.

It is noteworthy that all species of the Chrysopinae subgenus Chrysopodes (Neosuarius) Adams and Penny have their spiracular opening on Tergite 8 [35]-a presumed reversal to the pleisiomorphic state. In this group, where large series of specimens are available for comparative study, there appears to be developmental and interspecific variation in the extent and intensity of the tergite's lateral sclerotization, so that, in some specimens, especially those that are teneral, the spiracle appears to open on an unsclerotized portion of the pleuron membrane. If a similar situation occurs in the Nothochrysinae, it could present a confounding factor similar to that in Character number 1 above.

4.3.3. Future Studies. From the above, it is evident that the few adult characters currently used to explain the phylogeny of Nothochrysinae (the presumed basal chrysopid group) offer interesting but extremely limited information on the evolutionary history of the group and of the subfamily. Efforts to improve this situation have been hampered, in large part, 
by the lack of specimens (both adult and larval) for many of the rare, crucial taxa. It is hoped that the discussion here helps stimulate efforts to collect and study this ancient group so that future studies will be based on a broad ranging set of characters (from comparative adult and larval morphology, molecular studies, and comparative biology) and the full range of taxa.

\section{Conflict of Interests}

The author declares that there is no conflict of interests regarding the publication of this paper.

\section{Acknowledgments}

The author thanks Peter Duelli (Swiss Federal Research Institute WSL, Birmensdorf/Zurich, Switzerland) and Mervyn W. Mansell (University of Pretoria, Pretoria, South Africa) for generously providing the specimens of $K$. africana and Maurice J. Tauber for his helpful comments on the paper. The website "Lacewing Digital Library" (J. D. Oswald, chief editor) was helpful during this research [http://lacewing.tamu.edu/LDL/lacewingcitation.html]. The research benefitted from funding by the National Science Foundation, the USDA Competitive Grants Program, the National Geographic Society, and Cornell University (to Maurice J. Tauber and Catherine A. Tauber) and is part of Regional Project W-3185.

\section{References}

[1] P. A. Adams, "A review of the Mesochrysinae and Nothochrysinae (Neuroptera: Chrysopidae," Bulletin of the Museum of Comparative Zoology, vol. 135, no. 4, pp. 215-238, 1967.

[2] S. J. Brooks and P. C. Barnard, "The green lacewings of the world: a generic review (Neuroptera: Chrysopidae)," Bulletin of the British Museum of Natural History, Entomology, vol. 59, pp. 117-286, 1990.

[3] P. A. Adams and N. D. Penny, "Review of the South American genera of Nothochrysinae (Insecta: Neuroptera: Chrysopidae," in Current Research in Neuropterology: Proceedings of the 4th International Symposium on Neuropterology (24-27 June 1991, Bagnères-De-Luchon, Haute-Garonne, France), M. Canard, H. Aspöck, and M. W. Mansell, Eds., pp. 35-41, M. Canard (Privately Printed), Toulouse, France, 1992.

[4] S. J. Brooks, "An overview of the current status of Chrysopidae (Neuroptera) systematics," Deutsche Entomologische Zeitschrift, vol. 44, pp. 267-275, 1997.

[5] S. Winterton and S. de Freitas, "Molecular phylogeny of the green lacewings (Neuroptera: Chrysopidae)," Australian Journal of Entomology, vol. 45, no. 3, pp. 235-243, 2006.

[6] N. Haruyama, A. Mochizuki, P. Duelli, H. Naka, and M. Nomura, "Green lacewing phylogeny, based on three nuclear genes (Chrysopidae, Neuroptera)," Systematic Entomology, vol. 33, no. 2, pp. 275-288, 2008.

[7] C. A. Tauber, M. J. Tauber, and G. S. Albuquerque, "Debriscarrying in larval Chrysopidae: unraveling its evolutionary history," Annals of the Entomological Society of America, vol. 107, no. 2, pp. 295-314, 2014.
[8] V. J. Monserrat and L. M. Díaz-Aranda, "Los estadios larvarios de los crisópidos ibéricos (Insecta, Neuroptera, Chrysopidae), nuevos elementos sobre la morfología larvaria aplicables a la sistemática de la familia," Graellsia, vol. 68, no. 1, pp. 31-158, 2012.

[9] L. M. Diaz-Aranda and V. J. Monserrat, "Aphidophagous predator diagnosis: key to genera of European chrysopid larvae (Neur.: Chrysopidae)," Entomophaga, vol. 40, no. 2, pp. 169-181, 1995.

[10] L. M. Díaz-Aranda, V. J. Monserrat, and C. A. Tauber, "Chapter 4.3. Recognition of early stages of Chrysopidae," in Lacewings in the Crop Environment, P. K. McEwen, T. R. New, and A. E. Whittington, Eds., Cambridge University Press, Cambridge, UK, 2001.

[11] F. Brauer, "Larve von Hypochrysa nobilis Heyd," in Verhandlungen der Kaiserlich-Königlichen Zoologisch-Botanischen Gesellschaft in Wien, vol. 17, pp. 27-30, 1867.

[12] C. A. Toschi, "The taxonomy, life histories, and mating behavior of the green lacewings of Strawberry Canyon (Neuroptera, Chrysopidae)," Hilgardia, vol. 36, no. 11, pp. 391-433, 1965.

[13] T. R. New, "Some early stages of Dictyochrysa Esben-Petersen (Neuroptera, Chrysopidae)," Neuroptera International, vol. 1, no. 3, pp. 136-140, 1981.

[14] P. Duelli, H. Hölzel, and M. W. Mansell, "Habitat and larvae of the enigmatic genus Kimochrysa Tjeder (Neuroptera: Chrysopidae) in South Africa," in Proceedings of the 10th International Symposium on Neuropterology (22-25 June 2008, Piran, Slovenia), D. Devetak, S. Lipovsek, and A. E. Arnett, Eds., pp. 153-158, University of Maribor, Maribor, Slovenia, 2010.

[15] A. Rousset, Morphologie Céphalique des Larves de Planipennes (Insectes Névroptéroïdes), vol. 42 of Memoires du Museum Nationale d'Histoire Naturelle, Paris, Series A, Zoology, Éditions du Muséum, 1966.

[16] S. Tsukaguchi, Chrysopidae of Japan (Insecta, Neuroptera), S. Tsukaguchi, Aioi-cho 6-14-102, Nishinomiya-shi, Hyogo, 662 Japan (Privately published), 1995.

[17] C. A. Tauber, M. J. Tauber, and G. S. Albuquerque, "Berchmansus elegans (Neuroptera: Chrysopidae): larval and adult characteristics and new tribal affiliation," European Journal of Entomology, vol. 103, no. 1, pp. 221-231, 2006.

[18] P. A. Adams, "A new species of Hypochrysa and a new subgenus and species of Mallada (Neuroptera: Chrysopidae)," Pan-Pacific Entomologist, vol. 54, no. 4, pp. 292-296, 1978.

[19] T. R. New, "A revision of the Australian Chrysopidae (Insecta: Neuroptera)," Australian Journal of Zoology, Supplementary Series, vol. 28, no. 77, pp. 1-143, 1980.

[20] D. E. Kimmins, "A revision of the genera of the Apochrysinae (Fam. Chrysopidae)," Annals and Magazine of Natural History: Series 12, vol. 5, no. 58, pp. 929-944, 1952.

[21] B. Tjeder, "Neuroptera-Planipennia, The Lace-wings of Southern Africa. 5. Family Chrysopidae," in South African Animal Life, B. Hanström, P. Brinck, and G. Rudebec, Eds., vol. 12, pp. 228-534, Swedish Natural Science Research Council, Stockholm, Sweden, 1966.

[22] D. E. Kimmins, "A new African Hypochrysa (Neuroptera)," Annals and Magazine of Natural History: Series 10, vol. 19, no. 110, pp. 307-308, 1937.

[23] H. Aspöck, U. Aspöck, and H. Hölzel, Die Neuropteren Europas, vol. 2, Goecke and Evers, Krefeld, West Germany, 1980.

[24] S. K. Ghosh, "Contribution to the taxonomical studies of Neuroptera (suborder Planipennia) from eastern India. III. 
Family Chrysopidae," Records of the Zoological Survey of India, vol. 86, pp. 329-354, 1990.

[25] C. Yang -K, "Neuroptera," in Agricultural Insects, Spiders, Plant Diseases and Weeds of Xizang, S. Zhang, Ed., vol. 1, pp. 191-222, Xizang Renmin Press House, Xizang, China, 1st edition, 1987.

[26] B. Kovanci and S. Canbulat, "A new species of the genus Nothochrysa McLachlan 1868 from northwestern Turkey (Neuroptera: Chrysopidae) with a key to western Palaearctic species," Annales de la Societe Entomologique de France, vol. 43, no. 2, pp. 165-168, 2007.

[27] U. Aspöck and H. Aspöck, "Phylogenetic relevance of genital sclerites of Neuropterida (Insecta: Holometabola)," Systematic Entomology, vol. 33, no. 1, pp. 97-127, 2008.

[28] S. L. Winterton, N. B. Hardy, and B. M. Wiegmann, "On wings of lace: phylogeny and Bayesian divergence time estimates of Neuropterida (Insecta) based on morphological and molecular data," Systematic Entomology, vol. 35, no. 3, pp. 349-378.

[29] P. A. Adams, "A new genus and species of Osmylidae (Neuroptera) from Chile and Argentina, with a discussion of Planipennian genitalic homologies," Postilla, vol. 141, pp. 1-11, 1969.

[30] F. M. Carpenter, "A revision of the Nearctic Hemerobiidae, Berothidae, Sisyridae, Polystoechotidae and Dilaridae (Neuroptera)," Proceedings of the American Academy of Arts and Sciences, vol. 74, no. 7, pp. 193-280, 1940.

[31] J. D. Oswald, "Revision and cladistic analysis of the world genera of the family Hemerobiidae (Insecta: Neuroptera)," Journal of the New York Entomological Society, vol. 101, no. 2, pp. 143-299, 1993.

[32] J. D. Oswald, "Rediscovery of Polystoechotes gazullai Navás (Neuroptera: Polystoechotidae)," Proceedings of the Entomological Society of Washington, vol. 100, no. 3, pp. 389-394, 1998.

[33] S. L. Winterton and S. J. Brooks, "Phylogeny of the Apochrysine green lacewings (Neuroptera: Chrysopidae: Apochrysinae)," Annals of the Entomological Society of America, vol. 95, no. 1, pp. 16-28, 2002.

[34] C. A. Tauber, G. S. Albuquerque, and M. J. Tauber, "Characteristics of the Loyola Navás male (Neuroptera: Chrysopidae: Apochrysinae)," Proceedings of the Entomological Society of Washington, vol. 107, no. 3, pp. 543-547, 2005.

[35] C. A. Tauber, "Revision of Neosuarius, a subgenus of Chrysopodes (Neuroptera, Chrysopidae)," ZooKeys, vol. 44, pp. 1-104, 2010.

[36] C. A. Tauber, F. Sosa, and G. S. Albuquerque, "Two common and problematic leucochrysine species-Leucochrysa (Leucochrysa) varia (Schneider) and L. (L.) pretiosa (Banks) (Neuroptera: Chrysopidae): redescriptions and synonymies," Zookeys, vol. 301, pp. 57-101, 2013.

[37] C. A. Tauber, F. Sosa, G. S. Albuquerque, and M. J. Tauber, "Adults and larvae of two Leucochrysa (Leucochrysa) species (Neuroptera: Chrysopidae): descriptions, biological notes, and relationships," Zootaxa, vol. 3750, no. 2, pp. 101-129, 2013.

[38] J. D. Oswald, "Two new South American species of the genus Kempynus Navás (Neuroptera: Osmylidae: Kempyninae," Proceedings of the Entomological Society of Washington, vol. 96, no. 2, pp. 367-372, 1994. 

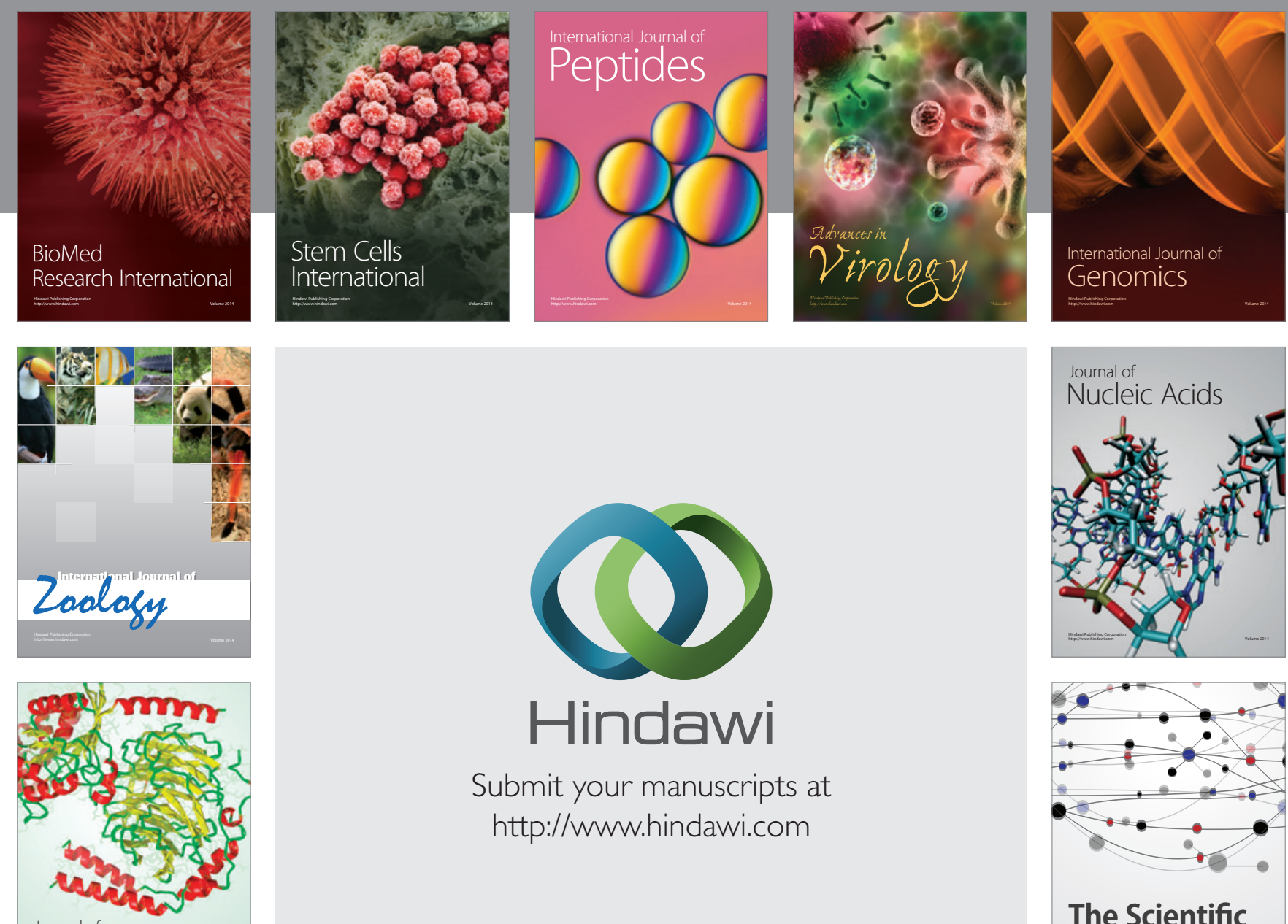

Submit your manuscripts at

http://www.hindawi.com

Journal of
Signal Transduction
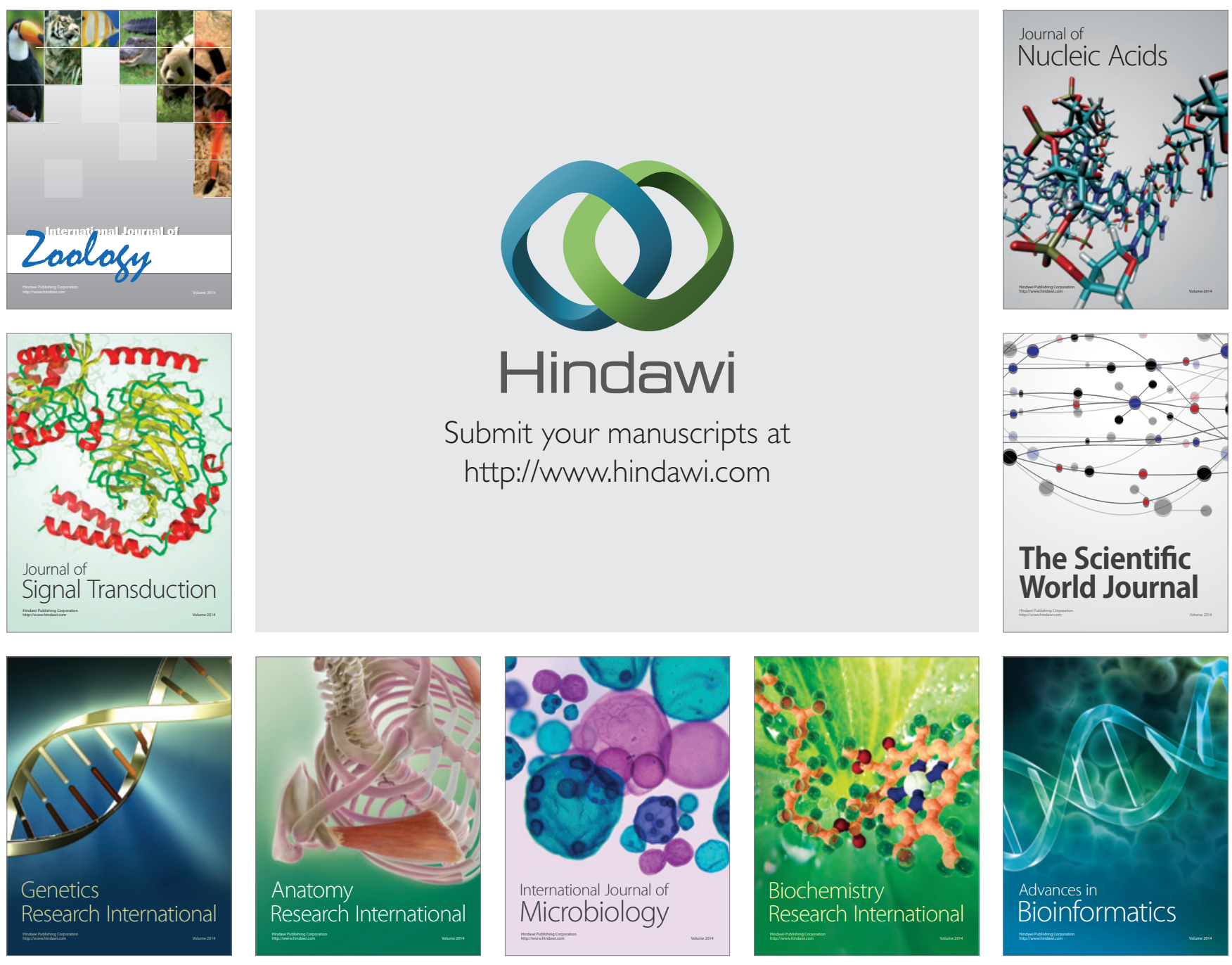

The Scientific World Journal
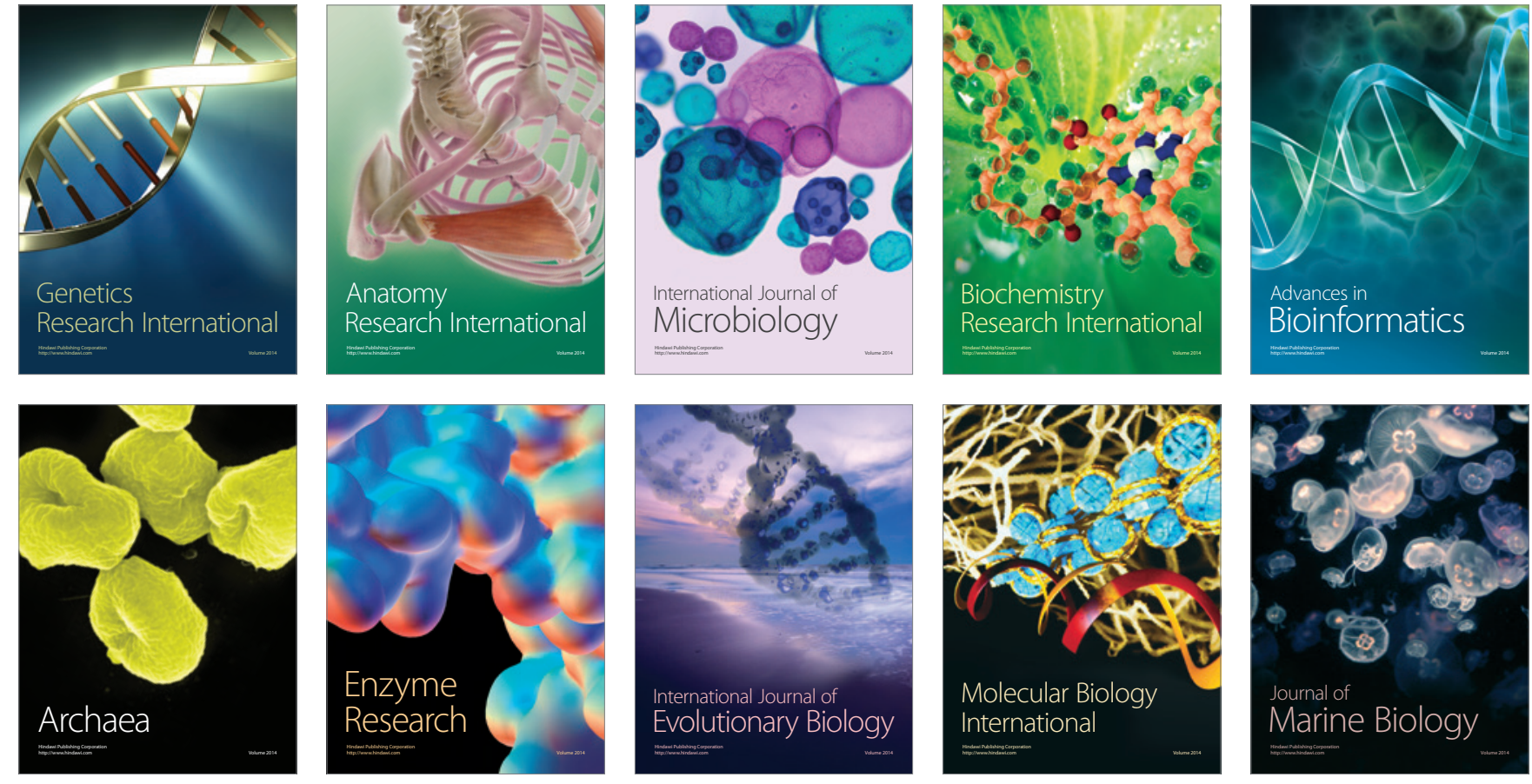